
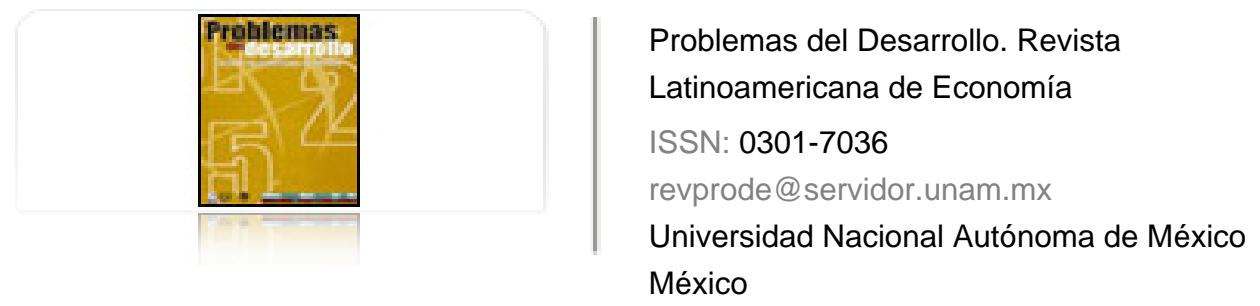

Levy Orlik, Noemí

Nuevo comportamiento de los bancos y su efecto en países con mercados financieros débiles: el caso de México

Problemas del Desarrollo. Revista Latinoamericana de Economía, vol. 36, núm. 141, abril-junio, 2005, pp. 59-84

Universidad Nacional Autónoma de México

Distrito Federal, México

Disponible en: http://www.redalyc.org/articulo.oa?id=11820075004

Cómo citar el artículo

- Número completo

- Más información del artículo

Página de la revista en redalyc.org

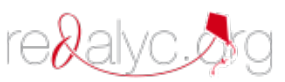

Sistema de Información Científica

Red de Revistas Científicas de América Latina, el Caribe, España y Portugal Proyecto académico sin fines de lucro, desarrollado bajo la iniciativa de acceso abierto 


\section{NUEVO COMPORTAMIENTO DE LOS BANCOS Y SU EFECTO EN PAÍSES CON MERCADOS FINANCIEROS DÉBILES: EL CASO DE MÉXICO}

\section{Noemí Levy Orlik*}

Fecha de recepción: 13 de diciembre de 2005. Fecha de aceptación: 25 de mayo de 2005.

\section{Resumen}

El objetivo de este trabajo es analizar el funcionamiento del sistema bancario mexicano a la luz de la teoría poskeynesiana de la endogeneidad del dinero y de los cambios institucionales ocurridos en las últimas tres décadas. Se argumenta que la contracción de los créditos bancarios se debe, por un lado, a la reducción de la demanda crediticia, de la independencia de la inversión respecto de la tasa de interés y de la disponibilidad crediticia y, por otro, a que los bancos pudieron reducir sus créditos por los crecientes márgenes financieros, provocados por una estructura oligopólica que limitó el desarrollo de los mercados financieros no bancarios. Lo anterior se explica por la dominación de los títulos gubernamentales en este mercado.

Palabras clave: bancos, teoría poskeynesiana, cambios institucionales, sistema financiero mexicano.

\section{Abstract}

The aim of this study is to analyze the functioning of the Mexican banking system in the light of the post-Keynesian theory of the endogeneity of money and of the institutional changes occurring in the last three decades. It is argued that the contraction of bank loans is due, on the one hand, to a fall in the demand for credit, the independence of investment with respect to the interest rate and the availability of credit; and, on the other hand, to the fact that the banks were able to reduce their loans thanks to growing financial margins resulting from an oligopolistic financial structure, which limited the development of the non-bank financial markets. This is explained by the domination of government securities in the financial market.

Keywords: banks, post-Keynesian theory, institutional changes, Mexican financial system.

Profesora titular B de tiempo completo definitivo, Facultad de Economía, unAM. Este trabajo es parte del proyecto PAPIITIN 302703. Agradezco el apoyo de Christian Domínguez Blancas en la elaboración de las estadísticas, así como los comentarios de los dictaminadores anónimos que leyeron este artículo. Es mi entera responsabilidad el contenido del mismo. Correo electrónico: levy@servidor.unam.mx 
Résumé

L'objectif de ce travail est d'analyser le fonctionnement du système bancaire mexicain à la lumière de la théorie postkeynesienne de l'endogénéité de l'argent et des changements institutionnels qui ont eu lieu dans les trois dernières décades. La discussion porte sur le fait que la contraction des crédits bancaires est due, d'un côté, à la diminution de la demande de crédit, à l'indépendance de l'investissement par rapport au taux d'intérêt et à la disponibilité de crédit; et d'un autre côté, au fait que les banques ont pu réduire leurs crédits par les marges financières croissantes, provoquées par une structure financière oligopolique, qui a limité le développement des marchés financiers non bancaires. Ce dernier point s'explique par la domination des titres gouvernementaux dans le marché financier

Mots clés: banques, théorie postkeynesienne, changements institutionnels, système financier mexicain.

\section{Resumo}

O objetivo deste trabalho é analizar o funcionamento do sistema bancário mexicano à luz da teoria poskeynesiana da endogeneidade do dinheiro e das mudanças institucionais acontecidas nas últimas três décadas. Se diz que a contração dos créditos bancários, deve-se, por uma parte, à redução da demanda creditícia, a independencia do investimento ao respeito da taxa de interesse e a disponibilidade creditícia; e, por uma oura parte que os bancos puderam reduzir seus créditos pelas crescentes margens financieras provocadas por uma estrutura financiera oligopólica, que limitou o desenvolvimento dos mercados financieros não bancários. O anterior explica-se pela dominação dos títulos guvernamentais no mercado finaceiro.

Palavras chave: bancos, teoria poskeynesiana, mudanças institucionais, sistema financeiro mexicano. 


\section{Introducción}

a organización bancaria mexicana sufrió drásticas modificaciones en los últimos treinta años, al adecuarse a la estructura financiera internacional dominada por la competencia de pasivos entre los diversos segmentos bancarios y no bancarios, y por los cambios institucionales relacionados con la desregulación y la globalización financiera propuestos, entre otros, por McKinnon (1974), Fry (1990) y Gurley y Shaw (1967).

En este contexto, se explica la imposición de los bancos múltiples en el sistema bancario mexicano en los años setenta, la reprivatización de la banca comercial en los noventa (nacionalizada en 1982) y el proceso de extranjerización de esas instituciones, iniciado en 1995 y casi finalizado en 2001, que afectó a todos los bancos, con excepción de uno (Girón y Levy, 2004).

Pese a que los cambios institucionales modernizaron y profundizaron el sistema, no se logró canalizar recursos financieros bancarios al desarrollo económico. Ello se debió a varios factores: primero, se redujo la demanda de créditos por parte de los prestatarios —acorde con la administración de pasivos—; segundo, los créditos se independizaron de la inversión y, tercero, los bancos se diversificaron: las utilidades provenientes de sus funciones tradicionales (créditos) perdieron importancia y mantuvieron una estructura que permite el predominio de utilidades de carácter oligopólico.

Los orígenes de estas explicaciones descansan en los postulados de la teoría endógena del dinero, la cual tiene diferentes posturas (que han tendido a unificarse). El propósito de este trabajo es determinar la causalidad relevante de la creación de dinero y detectar sus limitantes, para confrontarlos con la evolución del sistema bancario mexicano.

Este trabajo se divide en dos apartados. En el primero hay una revisión teórica de los postulados de Keynes acerca de la preferencia de la liquidez y el papel de los bancos en la emisión crediticia, reformulado por Minsky, con base en la hipótesis de inestabilidad financiera. A partir de ésta, surgen varias corrientes teóricas que, con base en el rechazo o aceptación de dichos postulados, resaltan las características relevantes del funcionamiento de la banca.

En el segundo apartado se estudia la causalidad de la creación de dinero bancario en el contexto del sistema financiero mexicano. Se resalta que la demanda crediticia determina la oferta y se revisa la composición de los portafolios bancarios para señalar las principales fuentes de utilidades de los bancos. El periodo de estudio comienza en 1985, por ser altamente complejo compatibilizar las estadísticas bancarias con metodologías anteriores. En algunos casos, se retrasa a 1990 por falta de información disponible.

\section{Desararrollo}




\section{Teoría endógena del dinero y funcionamiento de los bancos}

La teoría endógena supone que la demanda de créditos determina la oferta. Los bancos son las únicas instituciones capaces de crear liquidez independientemente de los recursos reales existentes; la emisión crediticia no los absorbe ni los utiliza (i.e., ahorros) porque la circulación de los medios de pagos privados, avalado por la banca central, tiene la capacidad de saldar deudas y demandar bienes y servicios, mediante la emisión de pasivos contra sí mismos (Keynes, 1936).

Las grandes controversias al interior de la teoría endógena del dinero giran en torno a las fuentes de utilidades de la banca y al efecto del banco central y los bancos comerciales sobre las tasas de interés activa y pasiva, y los elementos que restringen la oferta de créditos. Pese al creciente consenso acerca del carácter monetario de la tasa de interés como instrumento y la imposibilidad de controlar los agregados monetarios ${ }^{1}$ (i.e., predominio de la teoría endógena del dinero), existe desacuerdo en cuanto a la forma de operación de las instituciones bancarias. Esta discusión la iniciamos con el planteamiento de Keynes sobre la preferencia por la liquidez y el funcionamiento de los bancos.

\section{a) Keynes: preferencia por la liquidez y los límites al crédito}

Keynes postula que el movimiento de la tasa de interés se debe a cambios de las expectativas de los precios de los títulos financieros. En La teoría general de la ocupación, el interés y el dinero (1936) define la tasa de interés como una variable monetaria determinada por la oferta y demanda de dinero, cuya variabilidad se explica por el motivo especulativo que incide en el destino del ahorro: puede ser atesorado (hoarding) o canalizado al sistema financiero, convirtiéndolo en ahorro financiero o intencionado (Chick, 1983).

La variabilidad de la preferencia por la liquidez (motivo especulativo) se debe a las modificaciones en las previsiones de las ganancias (pérdidas) de capital que se originan por cambios en la tendencia de "la tasa de interés" (Keynes se refiere a la de largo plazo) que afecta el precio de los títulos y el monto del ahorro financiero.

Se critica este planteamiento en dos aspectos. Primero, incorpora implícitamente el concepto escasez de dinero al sostener que el ahorro total de la economía no recircula al sector financiero (Parguez, 2001); y segundo, la oferta monetaria se considera dada, lo cual fue interpretado como dinero exógeno. Minsky y los horizontalistas rechazan este argumento, aunque Chick (2001) y Chick y Dow (2002) señalan que debe entenderse a la luz las operaciones de mercado abierto, dominante en el periodo de Keynes.

Dalziel (2002) resalta la importancia de la tasa de interés desde la perspectiva de la teoría endógena del dinero. Blinder (1998), desde la perspectiva de la teoría dominante, rechaza la posibilidad de manipular los agregados monetarios. 
De acuerdo con Keynes (1936, capítulo 12), la circulación incompleta del ahorro al sistema financiero se explica con base en el funcionamiento del mercado de capitales, cuya característica principal es la inestabilidad financiera, resultado de la variación de precios de los títulos. El autor postula, a partir de ello, la necesidad de regular el movimiento de capital, a fin de garantizar la dominación de las previsiones de la corriente de espíritu empresarial. Con estas condiciones, los incrementos excesivos de los precios pueden ser neutralizados por intervenciones estatales (i.e., operaciones de mercado abierto, modificaciones de la tasa de fondeo del banco central, de otras tasas de préstamos o mecanismos de liquidez), con lo cual introduce un elemento de equilibrio (criticado por Minsky, 1987).

La incorporación del motivo financiamiento (1937), ausente en La teoría general, introduce la discusión de la creación dineraria, modifica la determinación de la tasa de interés y traslada la preferencia por la liquidez de los ahorradores al comportamiento de las instituciones bancarias. Keynes, al discutir el funcionamiento de los bancos, señala que la creación del dinero bancario (créditos) es resultado de su creciente demanda (ligada al incremento de la inversión planeada), lo cual no debe afectar a la tasa de interés; segundo, señala que la oferta crediticia depende de las expectativas futuras de los banqueros y, tercero, el banco central determina la tasa de interés, la cual se traspasa a las instituciones bancarias.

Los bancos pueden crear dinero, independientemente de los recursos reales existentes, por su capacidad de generar pasivos contra sí mismos, lo cual es considerado una operación contable (Keynes, 1936).

Los bancos comerciales satisfacen la demanda crediticia de los prestatarios solventes, la cual, de ser avalada por el banco central (i.e., función de prestamista de última instancia o intervenciones diarias de dicha institución central para garantizar la estabilidad del sistema de pago — operaciones de mercado abierto-) no modifica la tasa de interés. Empero, en el largo plazo, la mayor creación de dinero privado puede provocar la inestabilidad financiera que, de acuerdo con Keynes (1936), puede resolverse mediante el proceso del fondeo, el cual da pie a la noción de estabilidad en el sistema financiero.

El argumento se resume en la siguiente relación: aumentan los créditos bancarios por mayores gastos de inversión y sube el ahorro (resultado de la operación del multiplicador del ingreso), el cual de ser canalizado al sistema financiero (ahorro intencionado), anula los créditos bancarios y se empata la temporalidad de las deudas con los rendimientos de la empresa (véase Levy, 2001, capítulo 3).

\section{b) Minsky y la hipótesis de la inestabilidad financiera}

Este autor (1975) cuestiona que los determinantes del dinero propuestos por Keynes y la incertidumbre sean la causa fundamental de la variación de la tasa de interés. Minsky señala que ésta se modifica por cambios del nivel de la tasa de apalancamiento de los

\section{Desaarrollo}


demandantes y oferentes de créditos. Desde su perspectiva, el movimiento de la tasa de interés activa se relaciona con la oferta de créditos, determinada por los prestamistas (i.e., bancos) y la demanda de créditos por parte de los prestatarios, en la cual incide la tasa de descuento ("la tasa de interés") que se aplica a los rendimientos futuros. Se introduce el riesgo del prestamista y el prestatario en los precios de oferta y demanda, respectivamente, a partir de lo cual se define el volumen de créditos. La particularidad es que las tasas de interés activa y de descuento de los títulos financieros se modifican a lo largo del ciclo y están relacionadas con el gasto de la inversión.

La secuencia inicia con el gasto de la inversión seguido por la modificación de los niveles de apalancamiento de las instituciones bancarias y productivas - composición de los portafolios-, que induce ciclos económicos expresados mediante variaciones en los precios de la demanda y la oferta (Minsky, 1975:67) lo cual puede generar una crisis del mercado de capitales. Este autor resalta que el ciclo económico está sujeto a cambios constantes, con base en lo cual rechaza los posibles equilibrios ${ }^{2}$ y el proceso de fondeo. ${ }^{3}$

Debe resaltarse que desaparece la explicación de la preferencia por la liquidez (basada en el atesoramiento y el ahorro financiero) como la causante de los vaivenes de la tasa de interés y se rechaza al fondeo de la inversión como el garante de la estabilidad del sistema. En otras palabras, mayor volumen de créditos, aunque avalados por el banco central, están acotados por la estructura de portafolios.

\section{c) Extensiones de la visión estructuralista}

Los estructuralistas retoman de Keynes (1937) el concepto de la preferencia por la liquidez y, si seguimos la propuesta de Minsky, se traslada al término de comportamiento de los bancos. A partir de lo anterior, sostienen que éstos racionan créditos con base en sus expectativas del movimiento de la tasa de interés, pudiendo el banco central (o la política fiscal) influir en la emisión crediticia de los bancos comerciales. Desde esta perspectiva, la oferta monetaria tiene una pendiente positiva que se flexibiliza a raíz de los cambios institucionales; en el periodo de administración de pasivos se vuelve horizontal en el corto plazo (Chick y Dow, 2002). Por consiguiente, las relaciones institucionales dominantes son clave para entender la creación de dinero.

2 Minsky (1975:71 72) escribió: "La estabilidad no sólo es una meta inalcanzable, sino que siempre que se logra algo cercano a la estabilidad, se echan a andar procesos de inestabilización... [cada ciclo] lleva en sí el germen de su propia destrucción [más adelante, Misky refuerza] la sucesión de estados cíclicos no siempre se presenta con claridad en Teoría General".

3 Minsky (1991) señala que el concepto del fondeo es inapropiado para la fase del capitalismo desarrollado donde predominan los reportos, futuros y la titularización de deuda. 


\section{Preferencia por la liquidez de los bancos}

Chick y Dow (op. cit.) destacan la importancia de la tasa de interés como instrumento de política monetaria y, con base en ello, justifican la postura de Keynes acerca de una oferta monetaria dada o predeterminada, la cual explican mediante la relación entre sector bancario y mercado de títulos. ${ }^{4}$

El punto central de este argumento es que "los créditos bancarios crean dinero nuevo que afecta el precio de los títulos a través de la preferencia de la liquidez de los bancos y modifica el conjunto de la estructura de la tasa de interés" (ibid.:594). El banco central puede influir en esta operación (mediante instrumentos monetarios) con lo cual se resalta que la tasa de interés y la cantidad de dinero (en ésta se incluye el conjunto de agregados monetarios: dinero líquido, depósitos y bonos de corto y largo plazos) no son independientes.

Las autoras, basándose en Sayers, argumentan que si el objetivo de la política monetaria es mantener la tasa de interés estable, el volumen de dinero se vuelve endógeno (la razón liquidez a activos es relevante). Empero, si el fin es controlar los depósitos de los banqueros (reservas de caja o en el banco central) dicha tasa deja de ser una variable objetivo y se vuelve semiendógena.

En el análisis del comportamiento de los bancos se incorporan varias ideas relevantes: primero, su utilidad no descansa únicamente en la emisión crediticia, ajena a la iniciativa de los bancos, y así la compra de títulos (iniciativa de ellos para incrementar las utilidades) se vuelve significativa. Por consiguiente, la diversificación de las carteras es un elemento central y, con ello, Chick y Dow introducen un conjunto de tasas de interés [siguiendo la crítica de Tobin (1978) y Minsky (1975) a Keynes, acerca de que la demanda de dinero no puede concentrarse en una tasa de interés]. Segundo, la estructura de mercado se convierte en aspecto fundamental del funcionamiento de los bancos, con base en lo cual - como se señaló anteriormente- se explica la variación de pendiente de la oferta de dinero.

En condiciones de mercado bancario oligopólico (prevaleciente en Inglaterra hasta 1971 y predominante en el periodo de Keynes), dominado por la administración de los activos y un aumento de la tasa de interés administrada afecta, por igual, al conjunto de la estructura de la tasa de interés. ${ }^{5}$

4 La demanda y oferta de créditos es función de la tasa de interés activa (prime interest rate) y "la tasa de interés". Los bancos pueden emitir créditos o comprar bonos y (algunos) prestatarios emiten títulos o demandan los créditos. La emisión de éstos incrementa los depósitos, desplaza la oferta monetaria y se reduce "la tasa de interés", a medida que incrementa el precio de los títulos (Chick y Dow, 2002:592 593).

5 La estructura de la tasa de interés tiene la siguiente forma: $t i_{A}>t i_{B}>t i_{B C}>i_{A C P}>i_{D}$ que corresponde a la tasa de interés de préstamos, bonos, banco central, activos de corto plazo y depósitos, respectiva mente. Véase Chick y Dow (2002).

\section{DeSaarrollo}


Los bancos no compiten por tasas de interés; sus ganancias se basan en la composición de activos. Las variaciones de la tasa de interés inducen cambios en las preferencias de liquidez del conjunto de los agentes financieros, incluyendo a los bancos, y se expresa mediante movimientos de la composición de los portafolios financieros.

Un aumento de la tasa del banco central incrementa la tasa de interés de préstamo y reduce la demanda y oferta crediticia, lo cual resalta el planteamiento de Keynes acerca de la relación negativa entre inversión y tasa de interés. Asimismo, mayores tasas de depósitos - aunque bajan estos niveles por la reducción de créditos-, incentivan la compra de títulos de corto plazo. Esto ejerce una presión alcista sobre $i_{s}$ el cual, por lo general, es reforzado por intervenciones del banco central - la política de hacer efectiva la tasa del banco central y la liquidez puede desplazarse desde el sistema bancario hacia el mercado de títulos de corto plazo- - Un efecto adicional es que sube la tasa de interés de los bonos - largo plazo-, lo que provoca pérdidas de ganancias y da pie a que los agentes se adelanten, vendan sus activos y adquieran depósitos o bonos de corto plazo, dependiendo de la política monetaria.

La situación es diferente en un mercado financiero con estructuras competitivas. Los bancos compiten por depósitos con segmentos financieros no bancarios y los costos de fondeo bajan al operar en los diversos submercados financieros. Por consiguiente, en la administración de pasivos se despliega una competencia de tasas de interés entre los bancos (y con los segmentos financieros no bancarios). La estructura de las tasas de interés se modifica y la política monetaria pierde fortaleza (Toporowski, 2000); los bancos, en búsqueda de crecientes rendimientos, aumentan sus activos (emisión de créditos o compra de títulos) con los bajos costos de captación.

En una estructura de mercado competitivo desaparece el coeficiente de requerimiento legal de reservas (i.e., el techo de las tasas de interés, los depósitos de los banqueros en la institución central, el direccionamiento de los créditos, entre otros) y se imponen los requerimientos mínimos de capitales (CAR, por sus siglas en inglés), lo cual modifica la composición de la hoja de recursos bancarios: incrementa la compra de títulos y cae la emisión crediticia (son sujetos de crecientes reservas por sus mayores riesgos). Se vuelve atractiva la titulación de deuda (securitización) y se desarrolla el mercado de reportos (se incentiva el mercado de dinero) que emite liquidez para los bancos. La tasa de reporto es el principal conducto de la política monetaria, con un efecto traspaso menor sobre la tasas de préstamos y los depósitos. Un efecto fundamental de esta nueva estructura de mercado es la menor sincronía del movimiento entre las principales tasas de interés de mercado con relación a la de reportos, manteniéndose sólo una relación directa entre dicha tasa y la de títulos de mercado de corto plazo.

Se conserva la política monetaria con base en la tasa de interés objetivo y los bancos aumentan sus utilidades mediante sus predicciones en cuanto al movimiento de la tasa de 
interés, la cual no se mueve en línea con la tasa de interés líder del banco central; emergen las comisiones por servicios y pagos como importantes fuentes de utilidades de los bancos comerciales y se diversifica la composición de los recursos de estas instituciones. Se reduce la participación del financiamiento bancario en la producción y se desarrolla el comercio con instrumentos financieros sintéticos.

La adaptación de este planteamiento a los mercados emergentes (v.g., México) choca con la reducida diversificación de los financieros (predominan los títulos gubernamentales) provocando que los bancos tengan como objetivo abaratar los costos de fondeo con base en la ampliación del margen financiero (diferencia entre tasas de interés activa y pasiva).

Entonces, pese a la diversa composición de los recursos en el portafolio de los bancos, éstos, al adaptarse a las condiciones financieras internacionales, mantienen su margen basados en menores tasas de depósitos (la tasa de interés activa tiene un techo por la competencia intrabancaria que ocurre a partir de la globalización del sistema financiero y la extranjerización de la banca) y en mayores comisiones y tarifas que desalientan el ahorro financiero bancario por la reducida oferta de instrumentos finacieros no bancarios.

\section{Control del dinero mediante gasto fiscal}

Wray $(1998,2004 b)$, con base en la definición dinero-estado, señala que la oferta monetaria tiene una porción vertical y otra horizontal.

La porción vertical responde a la emisión de dinero fiduciario como resultado de los gastos del gobierno federal (en bienes y servicios) y del banco central (compra de oro, moneda extranjera y descuentos de activos que éste retiene) lo cual, después de pagar impuestos, queda en manos de los agentes privados. Es decir, genera atesoramiento de dinero fiduciario en manos del público y de los bancos, y tiene lugar una relación positiva entre el aumento del déficit y la liquidez de la economía, cuya distinción es reducir la tasa de interés, causalidad inversa a la señalada por la teoría dominante.

La porción horizontal indica que la oferta crediticia se adapta a la demanda y que las presiones sobre la tasa de interés se resuelven con operaciones de mercado abierto, con la particularidad de que la caída del déficit gubernamental suele restringir la emisión crediticia, lo cual puede desatar una deflación por activos (Wray, 2004b).

El motor del crecimiento económico descansa en el déficit fiscal desligado de la tasa de interés (Wray, 1998). El banco central, basado en una política de tasa de interés objetivo, absorbe los excesos de reservas (resultados de crecientes déficit fiscales) mediante la venta de bonos o acuerdos de recompra en el mercado interbancario. ${ }^{6}$ También se despliegan

\footnotetext{
${ }_{6} \quad$ Wray (1998:117) aclara: si el déficit es crónico, el banco central deberá vender bonos en el mercado primario para retirar de manera efectiva el exceso de reservas. Empero, si dicho déficit es temporal, pueden establecerse ventas con base en acuerdos temporales o definitivos en el mercado secundario.
}

\section{Desaarrollo}


operaciones de coordinación entre el banco central y la tesorería gubernamental, mediante transferencias de depósitos del gobierno en el banco central desde (o hacia) la banca comercial, para neutralizar los movimientos de reservas que deben revertirse cuando éstas caen (i.e., pago de impuestos).

La tasa de interés objetivo del banco central (señalada por la interbancaria) se ve influida por movimientos de la que corresponde a los bonos del tesoro, con base en decisiones gubernamentales desligadas de movimiento de empleo (o desempleo), cambios inflacionarios y objetivos del tipo de cambio. ${ }^{7}$

Por consiguiente, Wray se acerca tanto a los horizontalistas al señalar que la tasa de interés está determinada por el banco central —independientemente del ciclo económicocomo a los estructuralistas, al argumentar que la emisión de créditos bancarios puede estar limitada por el déficit fiscal.

Este planteamiento tiene dos problemas en el contexto de las economías emergentes. Primero, el incremento de la cantidad de dinero mediante el déficit fiscal está desligado del gasto de inversión e, incluso, del gasto corriente gubernamental, y no recircula al sistema bancario. Una porción importante se canaliza a intermediarios financieros (banca, inversionistas institucionales) que pueden extraerlo del espacio económico o no circularlo al sistema bancario ni al sector productivo. Segundo, la demanda de títulos financieros (por agentes externos) está condicionada a la rentabilidad de la economía con exigencias que impiden el crecimiento. Por un lado, el capital externo demanda bajos niveles de déficit gubernamental y, por otro, sus influjos elevan el riesgo cambiario.

Rechazo de la teoría de la preferencia por la liquidez horizontalista: oferta monetaria perfectamente elástica

Los horizontalistas, encabezados por Kaldor y Moore, rechazan la teoría de la preferencia por la liquidez (Rochon, 2001). Desde esta perspectiva, la incertidumbre incide en el gasto de la inversión y, por tanto, sólo afecta a la inversión planificada. Por consiguiente, el motivo especulación y el atesoramiento no afectan el movimiento de la tasa de interés que está determinada por el banco central.

El dinero tiene un valor extrínseco que proviene de su función como medio de pago e incentiva el gasto; además, es endógeno pues aparece como un flujo/pasivo cuya contrapartida es el crédito, el cual es un flujo/activo que concluye como un residuo de la tenencia de dinero. Por tanto, al final del circuito monetario, el dinero se transforma en un

Wray (2004c) señala que se está creando un nuevo consenso de política monetaria cuyos principales componentes son: transparencia (anuncio de los objetivos de política económica provocado por presión política), gradualismo (los objetivos de política son de largo alcance y no se espera obtener resultados rápidos) y activismo (el banco central no sigue reglas sino políticas discrecionales). Desde la perspectiva de este autor, las tasas de interés responden preferentemente a objetivos distributivos (Wray, 2004a). 
stock/activo que se distribuye entre las familias, que pueden atesorarlo o canalizarlo al sistema financiero (i.e., preferencia por la liquidez). La diferencia con Keynes es que la tasa de interés no es sensible a la distribución del ahorro; desaparece el motivo de la incertidumbre de la demanda de dinero y su atesoramiento.

La tasa de interés es exógena, determinada por el banco central, y está desligada de la incertidumbre. Incide en su determinación una función de reacción del banco central, en la cual se incluyen variables económicas ${ }^{8}$ y de carácter político. Por su parte, la oferta de reservas del banco central es endógena, pudiendo sólo modificar el costo de los fondos adicionales. La curva de la oferta monetaria es horizontal y se desplaza hacia arriba o hacia abajo conforme cambia la tasa de fondeo de dicho banco. Parguez (2001) critica esta postura porque, de ser muy continua la variación del costo del fondeo, puede provocar una curva con pendiente positiva.

La tasa de interés de préstamos es función del costo, por obtener fondos adicionales y un margen de utilidades (el cual refleja el grado de monopolio de los bancos, basado en sus rendimientos esperados) y un premio de riesgo de dichas instituciones que mide la preferencia de su liquidez (Rochon, 1999).

Desde la perspectiva de los horizontalistas, una vez definida la tasa de interés del banco central y el margen que adicionan los comerciales a la tasa de interés, dada una demanda de créditos, se determina la oferta crediticia que sólo puede ser modificada por los bancos mediante racionamiento, desligado de las variaciones de la tasa de interés. Éste depende del riesgo del prestamista que incluye los crediticios (posibilidad de impago), el de la tasa de interés (su modificación), y el de liquidez (la necesaria para enfrentar los depósitos).

Los horizontalistas resaltan que la tasa de interés es una variable distributiva que afecta la proporción del gasto entre las familias y las empresas (hay una estructura oligopólica que traspasa el mayor costo a los precios). Hay una relación positiva entre tasas de interés y precios, y negativa entre dichas tasas, salarios reales y gasto (siempre y cuando sea reducida la propensión marginal del consumo de los rentistas). Se rechaza la relación directa (negativa) entre tasa de interés e inversión (planteada por Keynes), reforzando con ello la argumentación de la independencia de dicha tasa respecto de la inversión y, por tanto, del ciclo económico, aunque en el largo plazo afecta a la inversión mediante la demanda efectiva.

Resumiendo, los bancos, en su deseo por incrementar las ganancias, acomodan todos los créditos elegibles (solventes) a la tasa de interés vigente, la cual está determinada por

8 Aunque la tasa de interés es considerada una variable administrativa, no es independiente de variables económicas como el estado futuro de la economía, la respuesta del sistema a cambios en la tasa de interés, los objetivos del tipo de cambio, el balance, pagos o el precio. Las condiciones políticas también inciden en la tasa de interés.

\section{DeSaarrollo}


el banco central y se integra como un costo de los créditos que las instituciones comerciales adicionan un margen, desligado del movimiento de la inversión.

Circuitistas: la estructura de tasas de interés

determinada por el banco central

Los circuitistas retoman el planteamiento de Wray (1998) según el cual el valor del dinero es extrínseco por estar relacionado al Estado (Parguez, 2001), quien genera gasto y crea valor. La diferencia es que no incide en la emisión de créditos bancarios.

El dinero es concebido como una deuda temporal, difundida por los bancos mediante la emisión de pasivos contra sí mismos, cual financia el gasto de los particulares y del Estado. Se destruye en la etapa de reflujo cuando los particulares y el Estado distribuyen títulos o venden sus productos y pagan los créditos. Aparece un mecanismo similar al fondeo, con la diferencia de que el dinero atesorado no incide en la tasa de interés, sino en las utilidades de los bancos (i.e., expresada por medio de la cartera vencida).

El motivo especulativo no se considera en la demanda de dinero porque el dinero atesorado es un activo financiero no sujeto a préstamos por parte de los bancos (Parguez, 2001). Con ello también rechaza la función de depósito de su valor.

La teoría del circuito monetario postula una exogeneidad fuerte de la tasa de interés (Parguez, op. cit.); ello implica que el Estado puede imponer una con base en sus objetivos de política monetaria, la cual, aunque logre los fines de la demanda agregada, puede no ser compatible con el nivel de la tasa de interés que estabilice el sistema bancario. Ello provoca que la política monetaria no sea independiente de la fiscal.

Se parte del supuesto de que la demanda de créditos crea su propia oferta (se rechaza la independencia entre la oferta y demanda crediticias), con lo cual se alejan del concepto escasez de dinero. Otro elemento importante es que el banco central determina la estructura de la tasa de interés sin considerar las fuerzas del mercado ni la inversión.

Hay un razonamiento similar al de Wray (1998), el cual señala que se emiten bonos para retirar excesos de reservas por crecientes déficit fiscales. Los bancos comerciales son tomadores de precios y determinan la tasa de interés activa añadiendo un margen. Ésta debe armonizar con su política de crecimiento y con los objetivos del banco central: el margen se explica con base en una teoría de funcionamiento de los bancos.

Dicho margen, que los bancos cargan sobre la tasa de interés del banco central, depende de los costos, los cuales incluyen salarios, intereses pagados a los depósitos y al banco central, y el ingreso por diferentes activos. Por tanto, el margen es función del crecimiento de sus utilidades, determinado por el crecimiento de su patrimonio en un nivel deseado y del ingreso que perciban por sus activos reales y financieros (incluidos los bonos del gobierno). 
A partir de este razonamiento se resalta que a mayor rendimiento de los bancos (en el cual influyen la tasa de bonos gubernamentales o del banco central) se reduce el margen sobre sus costos y, por consiguiente, la tasa de interés de créditos. Este planteamiento supone que las tasas de interés pasiva y activa se mueven en línea con la tasa de interés dominante del banco central, similar a la estructura oligopólica, en el contexto de administración de activos del planteamiento estructuralista, en el que hay una estructura de tasas que se mueve en concordancia con la tasa de interés del banco central y que debe armonizar el crecimiento económico con la rentabilidad del sistema bancario.

\section{La emisión crediticia y la diversificación de fuente de utilidades en el sistema bancario mexicano durante el periodo de desregulación y globalización}

En esta sección se analizan los principales mecanismos de creación de dinero y su efecto en la composición de los recursos de los bancos y la fuente de utilidades.

\section{a) Demanda de créditos}

Hay acuerdo en la teoría endógena de dinero en cuanto a que los bancos cubren la demanda de los prestatarios solventes. La presencia de los prestatarios insatisfechos se debe al racionamiento de créditos, el cual puede o no estar ligado a movimientos de la tasa de interés.

A partir de las estadísticas mexicanas es posible inferir una reducción de la demanda crediticia que tiene diversas explicaciones. Primero, se observa una reducción del coeficiente de la inversión en el producto con diversas fases cíclicas; segundo, el gasto de la inversión se desliga de los créditos y del movimiento de la tasa de interés, apareciendo fuentes alternativas de financiamiento no bancario [proveedores para las grandes empresas exportadoras (Leyva, 2002) y, especialmente, para las pequeñas y medianas empresas (Banco de México, Encuesta de evaluación coyuntural)]. Ello indicaría que el racionamiento de créditos es independiente de la tasa de interés (aunque la encuesta del Banco de México resalta que la tasa de interés es la principal razón aducida por los empresarios para no usar créditos). Ello cuestiona la hipótesis de inestabilidad financiera y debilita la propuesta de Keynes acerca de la relación negativa entre inversión y tasa de interés.

Con respecto al primer punto, es posible verificar que el componente de la inversión en el producto sufrió una caída importante en los primeros años de la década de los ochenta (en 1981 fue de $25 \%$ y descendió a 16\% en 1983), seguida por una atonía en el crecimiento del producto y la inversión (esta razón osciló alrededor de $14 \%$ entre 1984 y 1988). A partir de 1989 dicho componente creció (alcanzó un promedio de 20\%, cinco puntos debajo de 1982); se interrumpió entre 1995 y 1996, y se revertió entre 1997 y 2000, con niveles de composición de inversión similares a los inicios de la década de los noventa. En 2001 inició otra recesión (véase Gráfica 1).

\section{Desaarrollo}




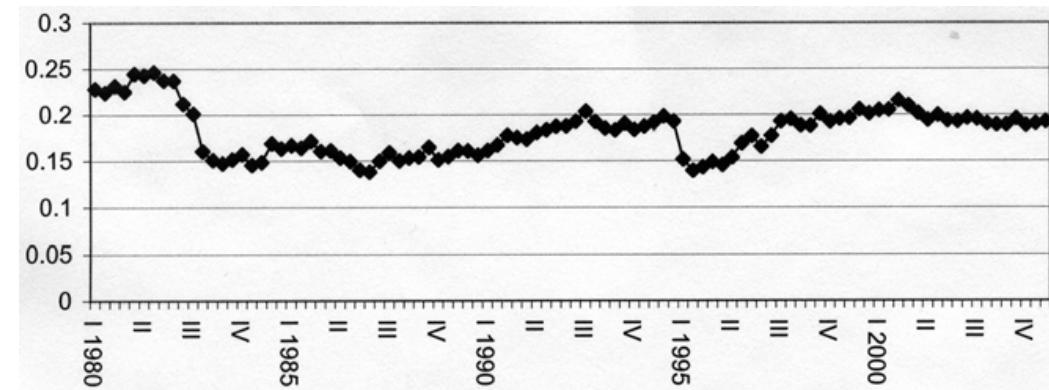

$\bullet$ FBKF/PIB

\section{Gráfica 1.}

FBKF: Formación bruta de capital fijo;

PIB: Producto interno bruto.

Fuente: elaboración propia con base en datos de INEGI.

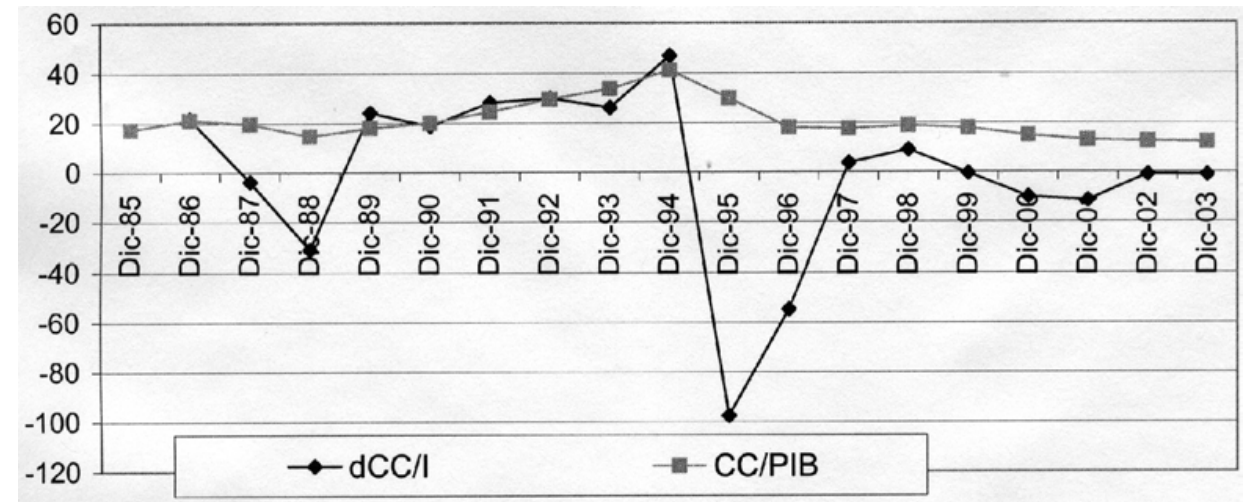

Gráfica 2.

DCC: variación de la cartera de créditos; I: formación bruta de capital fijo; CC: cartera de créditos (stocks);

PIB: producto interno bruto.

Fuente: elaboración propia con base en datos de INEGI y Banco de México. 


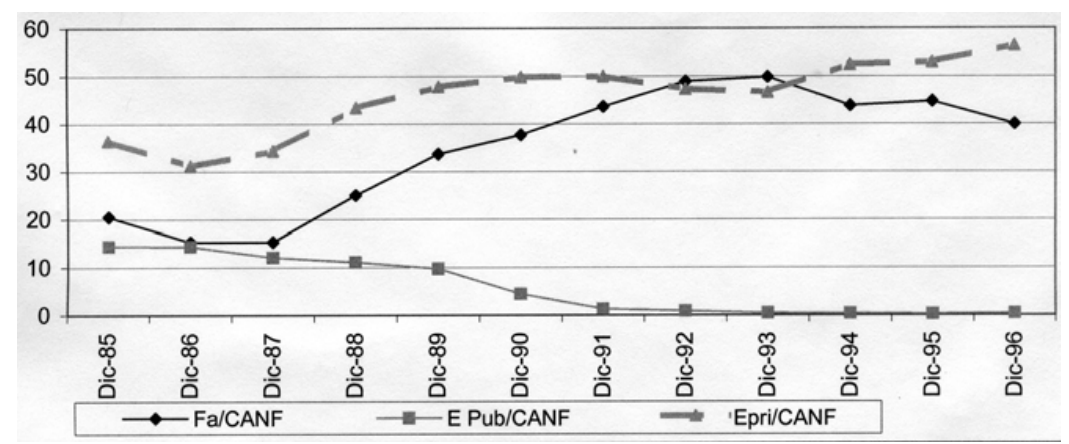

Gráfica 3

FA: créditos a familias; CANF: créditos a agentes no financieros; EPUB: créditos a empresas públicas; EPRI: créditos a empresas privadas.

Fuente: elaboración propia con base en datos de Banco México.

Si es válida la relación entre inversión y créditos, la caída de la participación de la inversión en el producto debería inducir a una reducción de los créditos durante los años ochenta, entre 1995-1996 y con posteridad a 2001, y debería presentarse un aumento entre 1989-1994 у 1997-2000.

Con respecto a la participación de la cartera de créditos en el producto, entre 1985 y 1989 esta razón no tiene gran variación, pese a que disminuyó el coeficiente de la inversión, canalizándose gran parte de los créditos al sector público en condiciones de reducción del gasto público corriente y de capital (véase Levy, 2001, capítulo 7). Entre 1989 y 1994 hubo una recuperación de la cartera crediticia con relación al producto, sin lograr los niveles de los años ochenta, parecido a un proceso minskiano. Este proceso se revirtió a partir de la crisis (entre 1994 y 1996 la relación stock de créditos a producto pasó de 41 a 16\%), y desencadenó una relación decreciente a partir del año que logró su mínimo histórico, 2003, con 12\% (véase Gráfica 2).

Los flujos crediticios (variación de la cartera de créditos) con respecto de la inversión reflejan un comportamiento similar: drásticas caídas en 1987 y 1988, así como en 1995, explicadas por las devaluaciones ocurridas en ese lapso, que presentaron flujos negativos entre 1999 y 2001, y cuyos primeros dos años se distinguieron por un fuerte crecimiento de la inversión (1999 y 2000) (véase Gráfica 2).

Estos resultados indican que hay una sola fase (1990-1994) en todo el periodo de globalización financiera, en el cual aparentemente la emisión de créditos (o flujos crediticios) estuvo relacionada con el producto (y la inversión).

Sin embargo, un análisis más profundo de la información estadística indica que los principales receptores de créditos (vigentes, redescuento y vencidos) entre los agentes no financieros fueron las familias (estadísticas disponibles de 1985 a 1996) con una participación creciente entre 1989 y 1994, situación que se revierte luego de la crisis. Después de 


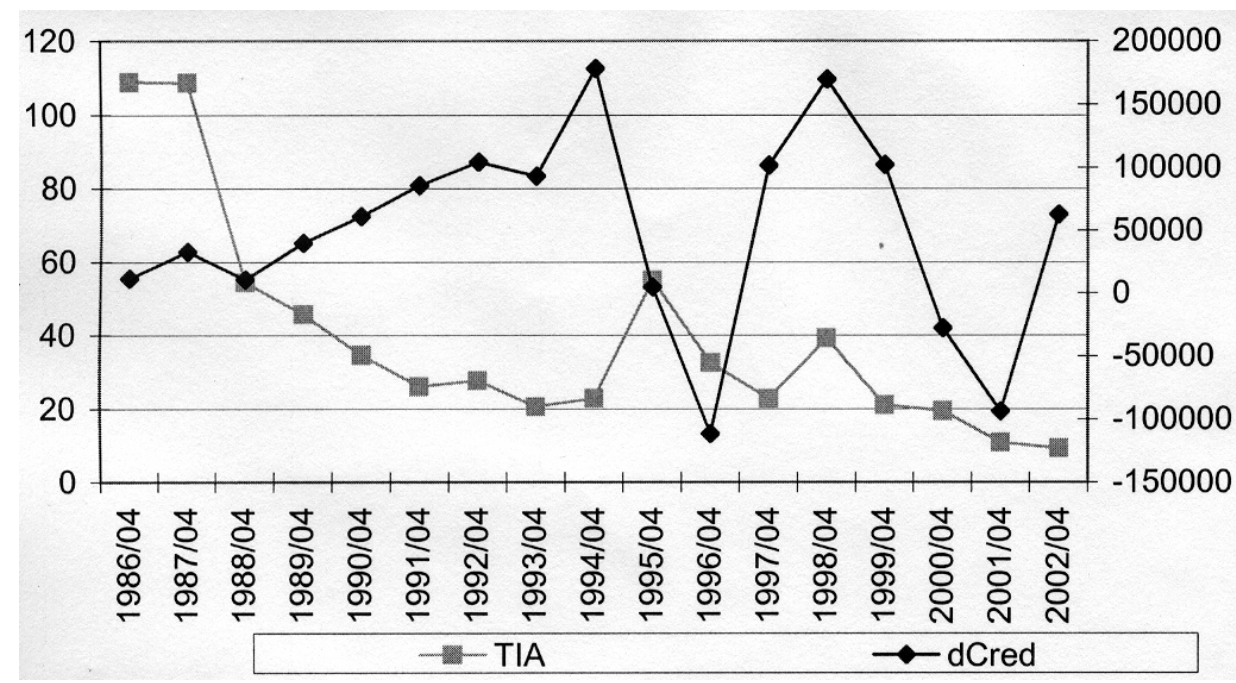

Gráfica 4.

TIA: tasa de interés activa; DCRED: variación de créditos.

Fuente: elaboración con base en datos de Banco de México y el FMI.

1994 las empresas privadas captan una proporción creciente de los créditos a los agentes no financieros (explicados por los compromisos pendientes y el aumento de los intereses; véase Gráfica 3). Por su parte, la cartera crediticia de la empresa pública (vigente, redescuento y vencida) tiene una tendencia hacia la baja como resultado del proceso de la privatización de las empresas estatales, lo cual refleja los efectos de la desregulación bancaria en la liberalización de recursos financieros para incrementar la disponibilidad del sector privado. Por consiguiente, no encontramos evidencia en el sistema financiero mexicano de la relación positiva entre el gasto de la inversión y los volúmenes crecientes de crédito, lo cual se vuelve más claro durante la segunda fase de recuperación del periodo de globalización (1997-2000), en el que incluso se presenta una reducción del flujo crediticio (1999-2001).

Un elemento adicional que contraviene el planteamiento de Keynes, Minsky y los estructuralistas es la falta de evidencia acerca de la relación negativa entre la tasa de interés y el flujo de créditos (Gráfica 4). Sólo se presenta la relación esperada entre 1989 y 1994, en un entorno de creciente canalización de créditos al sector privado no empresarial. Antes de 1989 y después de 1995, el comportamiento de la tasa de interés es completamente independiente del flujo de créditos.

Por consiguiente, una segunda conclusión es la relativa independencia entre el gasto de la inversión y el financiamiento bancario. Asimismo, se observa una relativa inelasticidad de los créditos con respecto de la tasa de interés, especialmente cuando ésta baja (véase Dow y Saville, 1990). 


\section{b) La composición de los recursos bancarios}

La reducción de la demanda de los créditos modificó la composición de los recursos bancarios, especialmente para diversificar sus fuentes de utilidades.

En México, la modificación de los recursos coincide con la desregulación bancaria y la globalización financiera que dinamizó los mercados de dinero y capital y, además, permitió el acceso de los agentes financieros bancarios y no bancarios a los mercados financieros internacionales. Se impone la administración de pasivos (Chick, 1990) con características muy particulares.

Desde nuestra perspectiva, la aparición de varios segmentos financieros no redujo la posición privilegiada que mantiene la banca comercial frente a las demás instituciones financieras. Por tanto, se mantuvo el régimen oligopólico al interior de la estructura bancaria.

En primer lugar, debe resaltarse que pese a la reducción de la demanda de los créditos, los recursos totales de la banca aumentan con respecto al producto interno bruto: entre 1985 y 1994 se duplican y retoman su crecimiento a partir de 2000 (cuando prácticamente culmina el proceso de extranjerización; véase Gráfica 5).

Las principales tendencias de la composición de recursos se pueden resumir en los siguientes aspectos: primero, hubo una reducción pronunciada de la participación de las dispo-

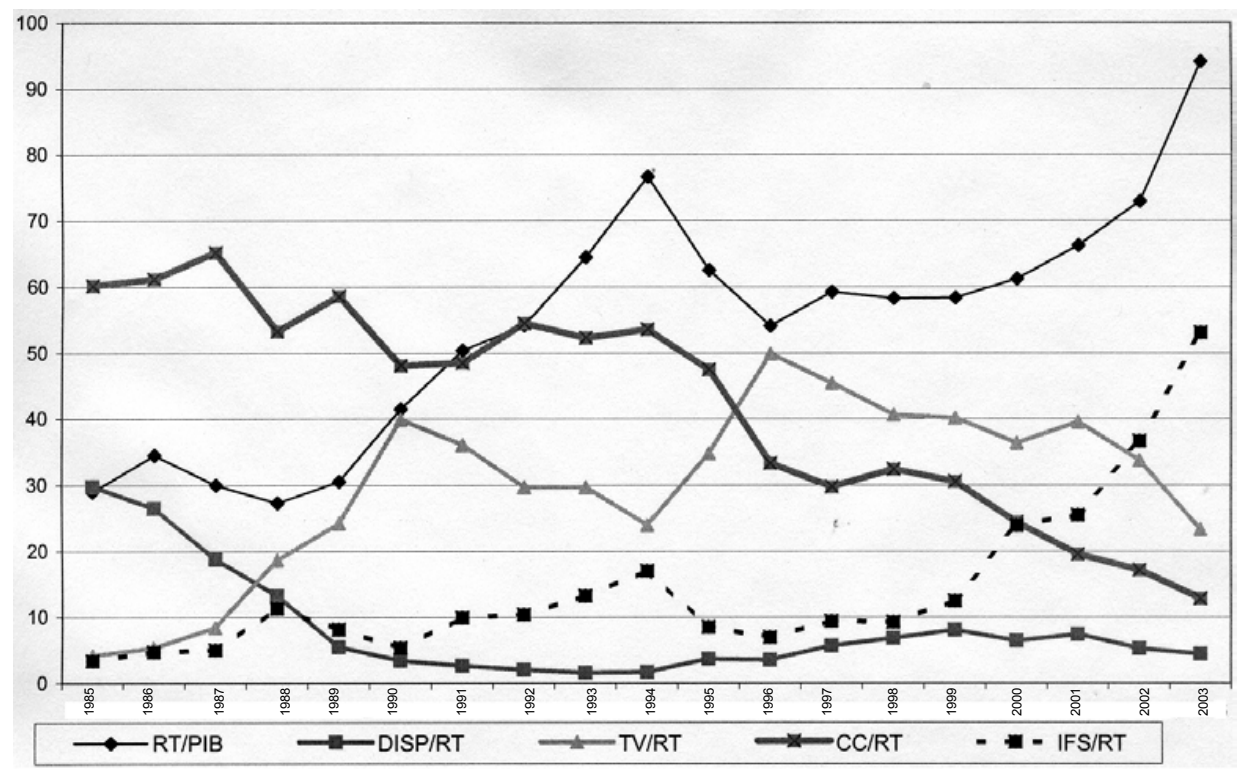

\section{Gráfica 5.}

TV: total de valores en posesión de los bancos; cc: cartera crediticia bancaria; IFs: instrumentos financieros sintéticos.

Fuente: elaboración propia con base en información estadística de Banco de México. 
nibilidades en los recursos bancarios a lo largo del periodo, lo cual fue resultado de la desaparición del encaje legal y de los depósitos obligatorios de los bancos comerciales en el banco central. En este fenómeno también incide la modificación del sistema de pagos (el de nóminas mediante tarjetas de débito) y el incentivo al uso de éstas en el pago de bienes y servicios que, además, reduce los costos de fondeo de la banca, por disponer recursos sin costo alguno.

Segundo, desde 1987 se observa una reducción constante de la cartera de crédito en la cartera total, incluso en el periodo de crecimiento económico, pese al incremento de los recursos totales en el producto. En 1985 este coeficiente representó 60\% de los recursos totales. En 1990, pese al incremento de la actividad económica y de la inversión, este coeficiente bajó a 48\%, revirtiéndose esta tendencia entre 1992 y 1994 (por encima de $50 \%$, sin lograr los niveles de los años ochenta).

A partir de 1995 tiene lugar una reducción constante de los créditos en los recursos totales (en 1996 fue de 33\% y cayó a 13\% en 2003). Este fenómeno fue acompañado de reducciones de la tasa de interés activa a niveles históricos (véase Gráfica 4), reforzándose el divorcio entre el financiamiento bancario y el producto.

Tercero, entre 1985 y 2000 se observa una participación ascendente de la cartera de valores en los recursos totales. En 1985 los valores representaron 4\% de los recursos totales, $40 \%$ en 1990, alcanzado en 1996, después de un breve descenso, una participación de 50\% que, en 1998, volvió nuevamente a bajar, logrando en 2003 una participación de apenas $23 \%$ (véase Gráfica 5). En este rubro deben resaltarse varios elementos: hasta 2000 los títulos gubernamentales fungieron como amortiguadores de la caída de recursos (véase Cuadro 1), aunque se modificó el tipo de instrumentos que emite la autoridad para intervenir en los bancos.

Inicialmente (1987 y 1989), los títulos del gobierno federal representaron casi la totalidad de la tenencia de los valores del sector bancario, lo cual obligó a lo que Sayers denominó "reforzar la política de incremento de la tasa de interés", con el objetivo de reducir la liquidez de la economía. Pese a que dichos títulos no perdieran importancia en el conjunto del sistema financiero, pierden relevancia en el sistema bancario - a partir de 1991 se canalizaron a los agentes no residentes y desde 1997 a las sociedades de inversión de los fondos de pensiones (SIEFORES).

Entre 1995 y 1999, los valores no negociables (incluidos todos los tipos de pagarés emitidos por el FOBAPROA, que posteriormente se conviertieron en los valores del IPAB) representaron casi la totalidad de la tenencia de valores (Cuadro 1). Debe considerarse que estos bonos fueron intercambiados por cartera vencida con rendimientos similares a los certificados de la tesorería (CETES), lo que proporcionó a los bancos, en dichos años, la mayor parte de su ingreso. 
Cuadro 1

\begin{tabular}{cccccccc}
\hline \multirow{2}{*}{ Diciembre de } & Ins. finan & \multicolumn{5}{c}{ Principales componentes de instrumentos financieros sintéticos } \\
a rec total & Futuros & Coberturas & Forwards & Opciones & Swaps & Derivados \\
\hline 1985 & 3 & 100 & 0 & 0 & 0 & 0 & 0 \\
1986 & 5 & 100 & 0 & 0 & 0 & 0 & 0 \\
1987 & 5 & 88 & 12 & 0 & 0 & 0 & 0 \\
1988 & 11 & 47 & 53 & 0 & 0 & 0 & 0 \\
1989 & 8 & 63 & 37 & 0 & 0 & 0 & 0 \\
1990 & 5 & 42 & 58 & 0 & 0 & 0 & 0 \\
1991 & 10 & 23 & 77 & 0 & 0 & 0 & 0 \\
1992 & 10 & 14 & 86 & 0 & 0 & 0 & 0 \\
1993 & 13 & 10 & 90 & 0 & 0 & 0 & 0 \\
1994 & 17 & 10 & 90 & 0 & 0 & 0 & 0 \\
1995 & 9 & 28 & 72 & 0 & 0 & 0 & 0 \\
1996 & 7 & 64 & 36 & 0 & 0 & 0 & 0 \\
1997 & 10 & 31 & 1 & 67 & 0 & 0 & 0 \\
1998 & 9 & 14 & 0 & 84 & 0 & 1 & 0 \\
1999 & 12 & 10 & 0 & 89 & 1 & 0 & 0 \\
2000 & 24 & 11 & 0 & 87 & 0 & 2 & 0 \\
2001 & 25 & 22 & 0 & 71 & 0 & 7 & 0 \\
2002 & 37 & 43 & 0 & 39 & 0 & 17 & 0 \\
2003 & 53 & 69 & 0 & 20 & 0 & 11 & 0 \\
\hline
\end{tabular}

Fuente: elaboración propia con base en información del Banco de México.

Una mención especial debe dedicarse a los reportos. Éstos adquieren relevancia a partir de 1990, mantienen una creciente participación hasta 1994, recuperan importancia desde el año 2000, aunque en menores proporciones (véase Cuadro 1). La composición de los reportos se conoce desde 1997 y, con base en ella, puede deducirse que están altamente influidos por títulos de carácter público (Cuadro 1); es muy reducida la emisión de préstamos bancarios con base en dichos instrumentos.

El análisis de la participación de la tenencia de valores en la banca muestra varias características importantes de los bancos y del sistema financiero mexicano. Primero, a lo largo de casi todo el periodo, la participación de los títulos privados en los recursos bancarios fue reducida. Ello refleja un mercado financiero poco profundo y delgado, pese a la desregulación bancaria y la promoción del mercado de títulos de deuda, el cual, como veremos más adelante, generó una estructura de tasas de interés que indujo utilidades bancarias oligopólicas. Segundo, en la mayor parte del periodo (hasta 2000) los bonos públicos actuaron como amortiguador del comportamiento de los recursos de los bancos. Cuando éstos descienden (por caídas del crédito) aumentan los primeros y reducen las oscilaciones de las utilidades bancarias. Incluso la banca comercial, en el periodo de privatización y extranjerización,tuvo una posición privilegiada porque el Estado, mediante el rescate bancario, redujo la caída de las utilidades, sin comprometer a los bancos para que asumieran su función de créditos (desde 1995 tiene lugar una caída constante de los créditos, y llegan algunos años a presentar flujos negativos).

\section{Desararrollo}


Finalmente, una alusión especial a los instrumentos financieros sintéticos. Entre 1989 y 1994, éstos tienen una participación creciente (pasan de 8.1 a 17.4\%), retoman su crecimiento desde 1999 y en 2003 explican más de la mitad de los recursos totales. Ello indica un cambio estructural del sistema bancario. A partir de 2000, cuando la banca comercial está dominada por la extranjera, dichos instrumentos crecen significativamente, lo cual refleja la adecuación de los bancos comerciales al entorno internacional.

A manera de recapitulación podemos señalar que: primero, la desregulación y la globalización financiera indujeron a una mayor penetración financiera, pese a la caída de la cartera de crédito. Los bonos de carácter público, en vez del crédito y los títulos privados, fueron el motor del crecimiento del dinero. Ello se debe a la menor demanda crediticia y, principalmente, a las opciones de inversión más redituables creadas por el gobierno para los bancos, pese a la diversificación del sistema financiero. Segundo, la composición de los activos bancarios mexicanos tuvo una diversificación parecida a la de los países desarrollados, como respuesta a los nuevos segmentos del mercado financiero, con la particularidad de que un reducido número de bancos controla casi la totalidad del mercado. Tercero, a partir de 2000 hay una caída de la participación de los títulos públicos, acompañada de una menor participación de créditos. Los bancos se mueven hacia la titularización de la deuda con una creciente participación de instrumentos financieros sintéticos, cuyo objetivo es proteger a los agentes de variaciones del tipo de cambio y de la tasa de interés. Todo esto conlleva un creciente riesgo sistémico para el mercado financiero, sin afectar a las instituciones bancarias en lo particular (Kregel, 1998; Eatwell y Taylor, 2000).

\section{c) Fuente de las utilidades bancarias}

Los indicadores globales de rendimiento bancario (ROE y ROA, sobre capital propio y sobre activos, respectivamente) muestran que las utilidades se recuperaron después de la crisis y, en el caso del ROA, alcanzó niveles superiores a los años previos a la crisis (véase Gráfica 6).

$\mathrm{Al}$ descomponer el ingreso total operado de la banca, entre sus principales rubros, encontramos que dominó el margen financiero ajustado (incorpora los ingresos por intereses y comisiones por créditos y por compra y venta de bonos, descontando los egresos por los mismos conceptos) (véase Gráfica 7). El margen financiero ajustado entre 1985 y 1998 (con una fuerte caída entre 1995 y 1997) representó casi 80\% del ingreso total operado. Desde 1999 se observa una drástica caída de la participación de este rubro en dicho ingreso.

Las comisiones y tarifas cobradas (por operaciones distintas a los créditos y la compra de bonos) tienen una participación ascendente, de manera especial desde 1994, que representó $30 \%$ de los ingresos totales operados en 2003. Ello indica que se neutralizó la caída de las utilidades bancarias como consecuencia de la crisis de 1995, mediante una combinación de altos intereses debidos a los valores no negociables del FOBAPROA y, posteriormente, del IPAB, altos intereses por concepto de valores gubernamentales - CETES - y una 


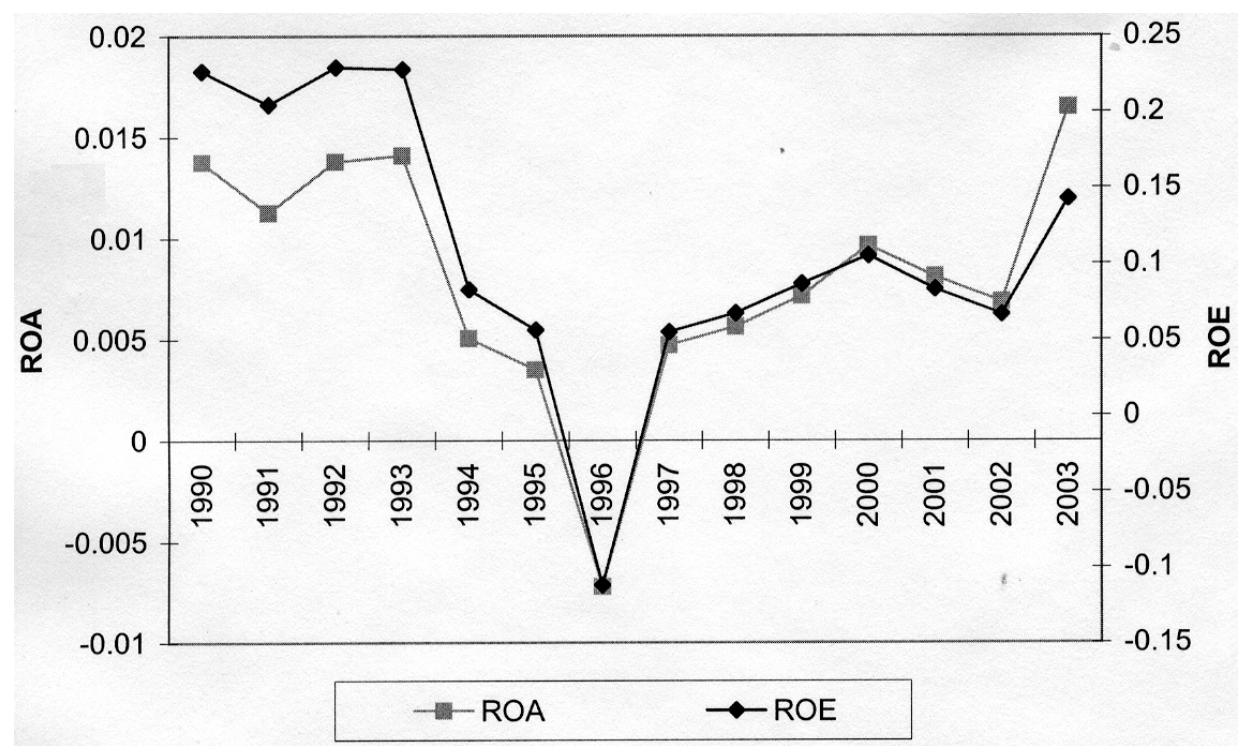

Gráfica 6.

ROA: rendimiento en relación a activos; ROE: rendimientos en relación a capital propio.

Fuente: elaboración propia con base en información estadística de la Comisión Nacional Bancaria y de Valores.

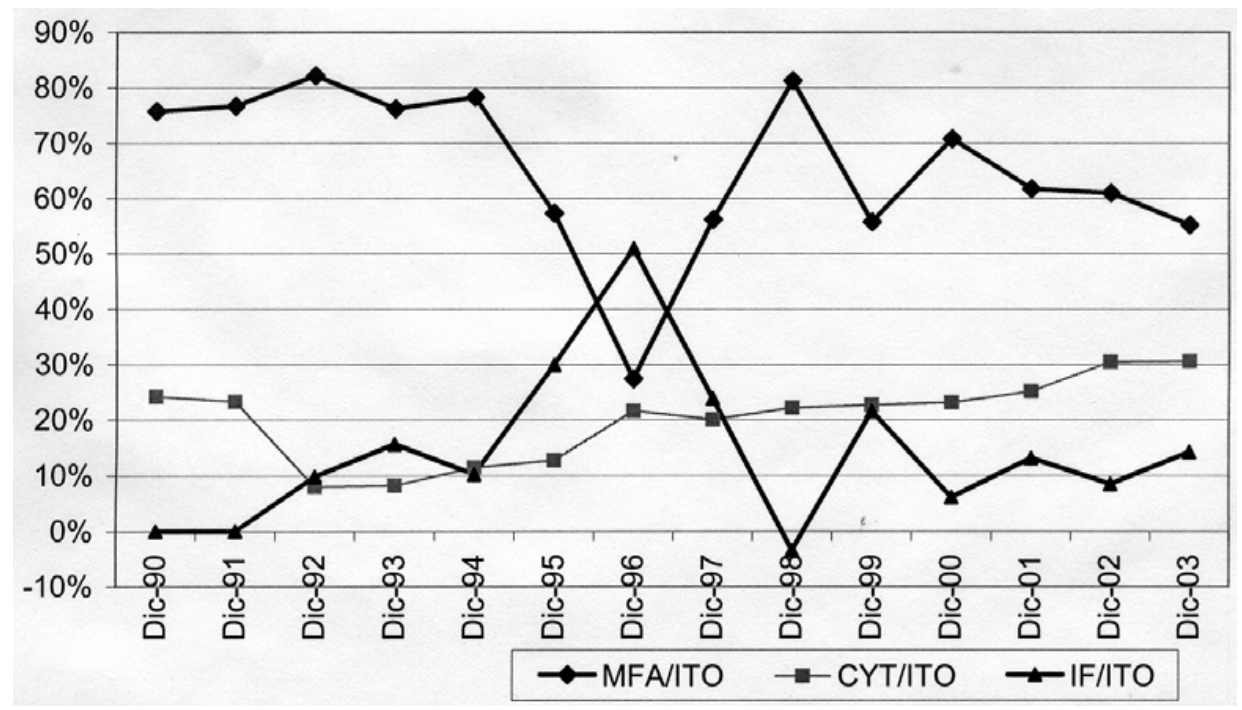

Gráfica 7.

MFA: margen financiero ajustado por riesgo; ITO: ingreso total de la operación; CYI: comisiones y tarifas netas; IF: resultado por inter-mediación financiera.

Fuente: elaboración propia con base en información estadística de la Comisión Nacional Bancaria y de Valores. 


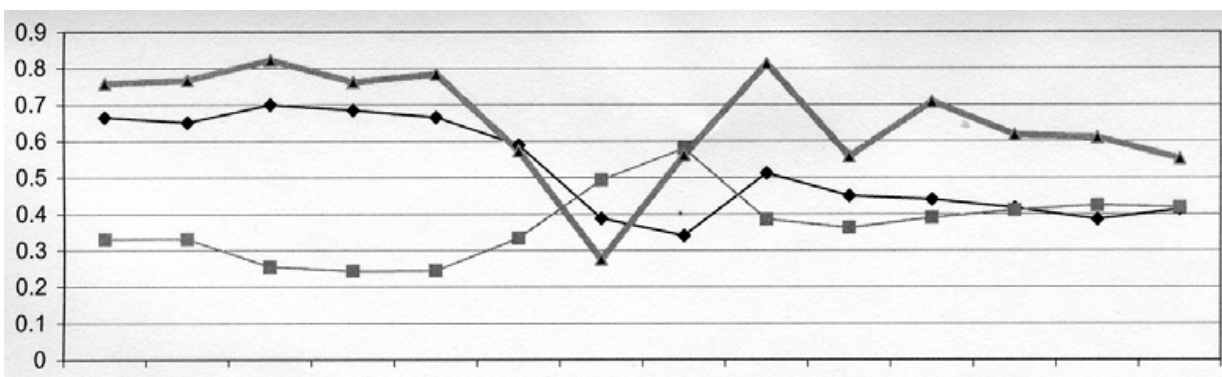

Dic-90 Dic-91 Dic-92 Dic-93 Dic-94 Dic-95 Dic-96 Dic-97 Dic-98 Dic-99 Dic-00 Dic-01 Dic-02 Dic-03

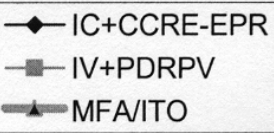

Gráfica 8.

IC: intereses a favor de créditos; CCRE: comisiones por créditos; EPR: estimación para riesgos crediticios; IV: intereses por valores; PDRV: premios devengados por reportos y préstamos de valores.

Fuente: elaboración propia con base en datos de la Comisión Nacional Bancaria y de Valores.

elevación de los ingresos por operaciones bancarias distintas a la emisión crediticia y compra y venta de bonos, con lo que se traspasaron las pérdidas de los bancos al resto de la sociedad. Específicamente, entre 1994 y 2003 el concepto de comisiones se incrementó más de $20 \%$ (véase Gráfica 7).

La intermediación financiera (compraventa de divisas, oro y plata y de valores por negociar y coberturas cambiarias) se incrementó drásticamente a partir de 1992 y llegó a representar 51\% del ingreso total operado en 1996. Ello se debe a que la liberalización financiera indujo operaciones de coberturas y la crisis de 1995 acrecentó estas operaciones.

Una revisión detallada de la participación de los diversos rubros en el ingreso devengado por intereses del margen financiero ajustado, diferenciando entre bonos y créditos, introduce otro elemento desestabilizador en el comportamiento de la banca (véase Gráfica 8). Entre 1985 y 1994 predomina el ingreso por emisión crediticia (intereses y comisiones menos estimación preventiva de riesgos crediticios) pese a la reducción de la participación de dicho rubro en los recursos totales. Lo anterior puede explicarse por el creciente margen entre la tasa de interés activa y la de los bonos del gobierno federal (Gráfica 9). Ello indica que el costo de fondeo bancario fue bajo durante dicho periodo y, pese a la globalización financiera y la competitividad entre los distintos segmentos financieros, los bancos comerciales mantuvieron su dependencia del banco central para fondear sus operaciones.

A partir de 1995 aumentó el ingreso por bonos (intereses y premios devengados por reportos y préstamos de valores). Inicialmente, ello reflejó el programa de rescate gubernamental de la banca (efecto amortiguador) y, posteriormente, tuvieron gran participación los reportos, instrumento fundamental de intervención de la banca central en la co-

\section{Desarrrollo}




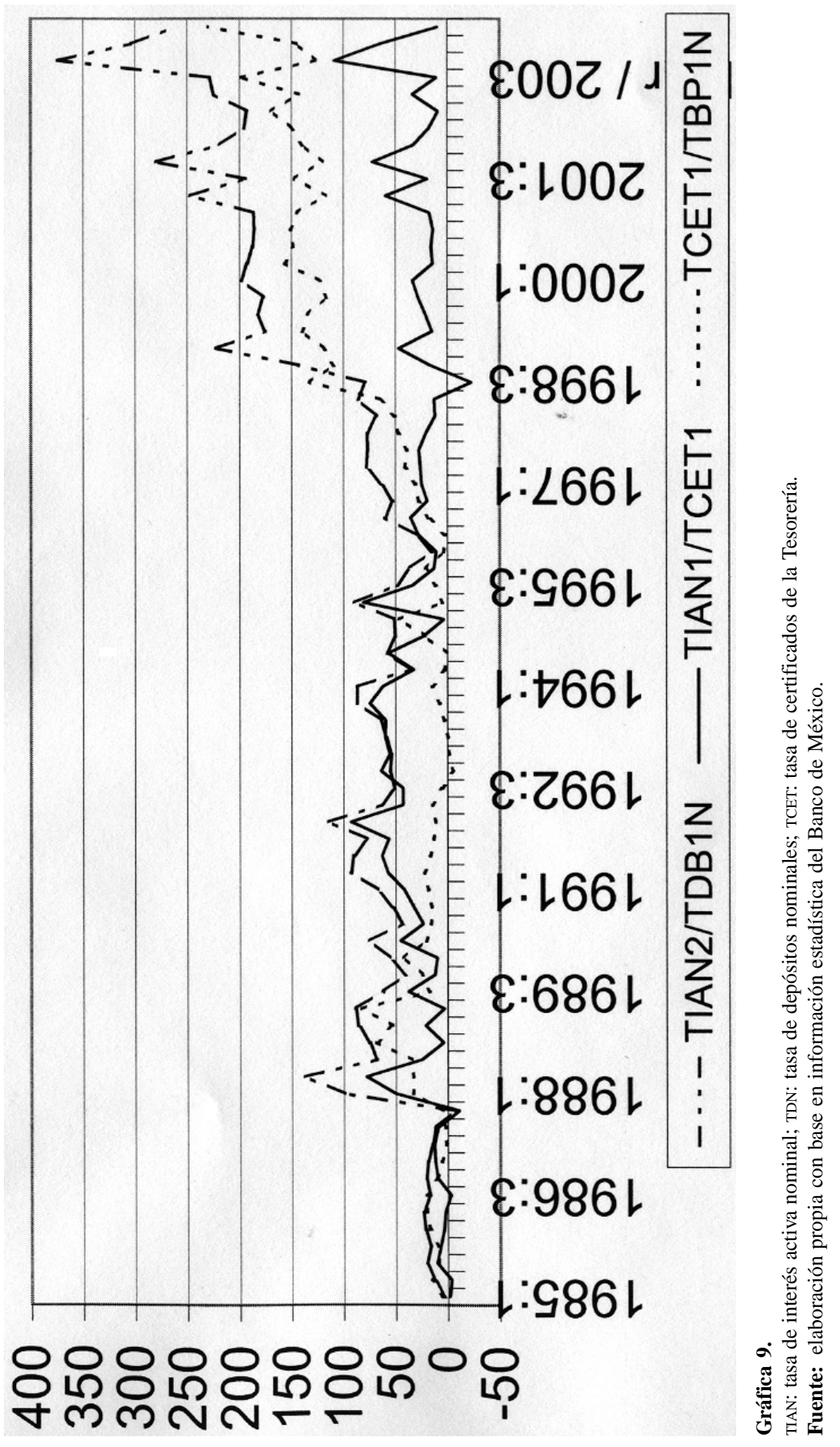

Desalus on 
mercial. Ello fue acompañado por un cambio en la estructura de la tasa de interés. Las tasas de interés de depósitos actúan como el ancla de las utilidades de la banca, con lo que se amplía el margen entre la tasa de los CETES y la de los depósitos, y se reduce el margen entre la tasa de interés activa y la de los CETEs (véase Gráfica 9). Medidas adicionales que incrementaron las utilidades bancarias son la creciente disponibilidad de liquidez por el cambio de pago de nóminas mediante tarjetas de débito, y las limitaciones al movimiento ascendente de las tasas activas, impuesto por la globalización financiera.

\section{Conclusiones}

El centro de la discusión en torno a la creación de dinero y el funcionamiento del sistema bancario se encuentra en los planteamientos de estructuralistas, horizontalistas y circuitistas, cuyos conceptos giran alrededor del rechazo o aceptación de la preferencia por la liquidez, la relación contraria entre inversión y tasa de interés, y el efecto de las va-riables monetarias sobre el ciclo económico.

Hay consenso en que los flujos financieros se crean independientemente de los recursos reales, en tanto los bancos satisfacen la demanda de créditos solventes. La diferencia se encuentra en la relación del racionamiento de créditos y la tasa de interés, y entre ésta y las reservas, así como en la determinación del margen de la tasa de interés activa.

Los circuitistas adoptan el concepto superexogeneidad de la tasa de interés y explican la composición de los recursos y la fuente de utilidades con base en una teoría del funcionamiento de la banca, resaltando que el racionamiento de créditos es independiente de dicha tasa. Las reservas son completamente exógenas y se rechaza la presencia del mercado de dinero. Asimismo, no es posible diferenciar entre la demanda y la oferta crediticia.

Los horizontalistas consideran que la tasa de interés es exógena y que el margen de la tasa de interés activa depende de la preferencia por la liquidez de los bancos, de igual manera que el racionamiento de créditos es independiente de la tasa de interés. Aunque rechazan la posibilidad de una curva de oferta con pendiente positiva, ésta puede aparecer mediante el concepto de preferencia por la liquidez de los bancos, que es independiente del ciclo económico.

Los estructuralistas argumentan que la política monetaria o fiscal puede modificar la liquidez de la economía, lo cual provoca que las reservas sean semiendógenas al sistema; existe una relación positiva entre racionamiento de créditos y tasa de interés y, por tanto, aceptan la relación entre inversión, tasas de interés y volumen de créditos, aunque resaltan aspectos institucionales que garantizan la liquidez al crecimiento económico. A partir de la crisis de los años treinta9 ${ }^{9}$ se establece la administración de activos que, posteriormente,

9 La crisis de los treinta provocó que los bancos centrales tuvieran como principal objetivo la estabilidad de los medios de pagos, independientemente del funcionamiento de los bancos, véase Aglietta (1996).

\section{Desarrrollo}


con la diversificación del sistema financiero, crea una situación competitiva en la estructura bancaria, con base en la cual introducen la horizontalidad de la oferta monetaria para el corto plazo. Ello genera una diversificación en las fuentes de utilidades y la independencia del fondeo de la banca con respecto de las políticas monetarias. La creación del dinero depende de los pasivos que la banca cree contra sí misma a causa de emisión crediticia o compra de títulos, con una reducida incidencia de los movimientos de la tasa de interés del banco central.

Al revisar la forma de dicha generación en el sistema financiero mexicano, encontramos cuatro elementos centrales que explican el movimiento del sistema bancario: primero, la reducción de la demanda de créditos produjo un descenso en la creación de dinero bancario con respecto de los recursos totales e independizó el gasto de la inversión en relación con la emisión de créditos y el comportamiento de la tasa de interés, lo cual se adaptaría a la posición horizontalista acerca del funcionamiento de los bancos.

Segundo, si seguimos el planteamiento estructuralista, la tenencia de bonos gubernamentales amortiguó la caída de los créditos y fue una importante fuente generadora de rendimientos para el sector bancario. La diferencia es que se explica por los crecientes rendimientos de los CETES con respecto de la tasa de depósitos. Esto, a su vez, amortigua el efecto de la caída de los créditos en las utilidades y provoca una estructura inadecuada de la tasa de interés, que impidió la promoción de títulos bancarios y privados. Ello evidencia una estructura oligopólica del sector bancario. En este contexto, el margen financiero se explica por la reducida diversificación del mercado de títulos, lo cual se opone al planteamiento de estructuralistas, horizontalistas y circuitistas. No se despliega el arbitraje que, por medio de mecanismos de mercado, iguala rendimientos de títulos similares.

Tercero, a partir de la extranjerización de la banca se acentuó la estructura oligópolica del sector porque no incrementó la disponibilidad de créditos y mantuvo la apropiación de ganancias extraordinarias, sin fomentar una mayor competencia en el mercado de títulos, mediante fondeo y bonos bancarios.

Cuarto, pese a las profundas reformas estructurales, los títulos gubernamentales predominaron de manera casi absoluta, originando amplias brechas financieras, que evidencia la particularidad del sistema financiero mexicano.

A partir del análisis de las utilidades bancarias se observa la incongruencia de la organización del sistema financiero mexicano con la estructura de la administración de pasivos y la superexogeneidad de la tasa de interés. La extranjerización mantuvo —e incluso profundizó - la estructura oligopólica del sector. La emisión crediticia no se reactivó y la brecha financiera creció.

\section{Desaarrollo}




\section{Bibliografía}

Aglietta, M., "Sistemic Risk, Financial Innovations and the Financial Safety Net", en G. Deleplace y E. Nell (editores), Money in Motion: the Postkeyenesian and Circulation Approaches, Nueva York, The Jerome Levy Economic Institute, 1996, pp. 552-581.

Banco de México, "Indicadores económicos", www. banxico.org. $m x$

_, "Encuesta de evaluación coyuntural del mercado de crédito", www.banxico.org.

Blinder, S.A., El banco central: teoría y práctica, Madrid, Antoni Bosch, 1998.

Chick, Victoria, La macroeconomía según Keynes, Madrid, Alianza Editorial, 1990.

, "Evolution of the Banking System and the Theory of Monetary Policy" en S.F. Frowen (editor), Monetary Theory and Monetary Policy: New tracts for the 1990s, Nueva York, St. Martin Press; Londres, Macmillan, 1993, pp. 79-92.

, "How best to study money", mimeo, UCL, Londres, 2001.

, y S. Dow, "Monetary Policy with Endogenous Money and Liquidity Preference: a non dualistic treatment", en Journal of Post Keynesian Economics, vol. 24, núm. 4, verano de 2002, pp. 587-607.

Comisión Nacional Bancaria y de Valores, Anuarios estadísticas e información, www.cnbv.gob.mx

Dalziel, P., "The Triumph of Keynes: what now for monetary policy research?, en Journal of PostKeynesian Economics, vol. 24, núm. 24, verano de 2002, pp. 511-528.

Dow, J.C.R. y I.D. Saville, A Critique of Monetary Policy. Theory and British Experience, Oxford, Claredon Press, 1990.

Eatwell y Taylor, Global Finance at Risk. The Case for Regulation, Nueva York, The New Press, 2002.

Fry, M.J., Dinero, interés y banca en el desarrollo económico, CEMLA-FELABAN, 1990, pp. 281-319

Girón, A. y N. Levy, México: ¡Los bancos que perdimos! De la desregulación a la extranjerización del sistema financiero; aprobado para publicar, México, IIEC/FE-UNAM, 2004

Gurley y Shaw, "Financial Structure and Economic Development", en Economic Development and Cultural Change, vol. 15 , núm. 3, abril de 1967, pp. 257-268.

INEGI, Información económica, www.inegi.gob.mx.

Keynes, J.M., La teoría general de la ocupación, el interés y el dinero, México, Fondo de Cultura Económica (serie Economía), 1986.

, "Alternative Theories of the Rate of Interest", en D. Moggride (editor), Collected Writings of John Maynard Keynes, vol. XIV, Londres, Macmillan, 1973, pp. 201-215.
Kregel, J.A., "Derivatives and Global Capital Flows: applications to Asia" en Cambridge Journal Economics, 1998, pp. 677-692

Levy, N., Cambios institucionales del sector financiero y su efecto sobre el fondeo de la inversión. México 1960-1994, México, DGAPA/ Facultad de Economía-UnAm/UABJo, 2001.

Leyva, L., "Análisis de las fuentes de financiamiento de las empresas bursátiles en México. 19921999", tesis de licenciatura, Facultad de Economía-UnAm, 2002,

McKinnon, R.I., Dinero y capital en el desarrollo económico, México, CEMLA, 1974, pp. 7-26.

Minsky, H., Las razones de Keynes, México, Fondo de Cultura Económica, 1987.

"The Endogeneity of Money", en E. Nell y W. Semmler (editores), Nicholas Kaldor and mainstream economics, Nueva York, St. Martin Press, 1991, pp. 207-220.

Parguez, A., "Money Without Scarcity: from the horizontalist revolution to the theory of the monetary circuit", en L.P. Rochon y M. Vernengo (editores), Credit, Interest Rates and the Open Economy: Essays on Horizontalism, Cheltenham, Edward Elgar, 2001, pp. 69-103.

Rochon, L.P., "Horizontalist and Structuralist Credit and Endogenous Money", en L.P. Rochon y M. Vernango (editores), Credit, Money and Producction: An alternative Post-keynesian Approach, Cheltenham, Edward Elgar, 1999, pp. $155-201$.

— , (2001), "Horizontalism: Setting the Record Straight", en L.P. Rochon y M. Vernango (editores), Credit, Interest Rates and the Open Economy: Essays on Horizontalism, Cheltenham, Edward Elgar, pp. 31-65.

Tobin, J., "Monetary Policies and the Economy: the transmission effect", en Southern Journal, vol. 44, núm. 3, 1978.

Toporowski, J., "The End of Finance: capital market inflation, financial derivatives and pension fund capitalism”, Cheltenham, Edward Elgar, 2000.

Wray, R., "Understanding Modern Money: The key to full employment and price stability", Cheltenham, Edward Elgar, 1998.

, "International Aspects of Current Monetary Policy", en CFEPS, working paper, núm. 32, marzo, 2004a.

, "The Credit Money and State Money Approaches", en CFEPS, working paper, núm. 34, abril, 2004b.

, "The New Monetary Consensus", en cFePs, working paper, núm. 36, septiembre, 2004c. 